\title{
FEMINIZAÇÃO DO HIV/AIDS E SUAS CONSEQUÊNCIAS: SABERES NECESSÁRIOS
}

Jaqueline de Andrade ${ }_{1}$, Arilda Inês Miranda Ribeiro ${ }^{2}$

${ }_{1}$ Discente do curso de Pedagogia na FCT/ UNESP - Presidente Prudente- SP. ${ }^{2}$ Docente da FCT/UNESP - Presidente Prudente- SP. E-mail: jaquelinepedagogia92@gmail.com).

\section{RESUMO}

A Adquired Immunological Deficiency Syndrome (AIDS) é uma doença infecciosa e os primeiros relatos surgiram em 1980, desde os dias atuais gera polêmicas e muitas questões equivocadas causando sérios impactos na sociedade. Este artigo tem por objetivo fornecer reflexões acerca da temática da Feminização do human immunodeficiency virus (HIV) no município de Presidente Prudente, bem como sobre as consequências da ausência do grau de escolaridade como um dos fatores do aumento dos casos de human immunodeficiency virus (HIV) entre as mulheres soropositivas. A metodologia utilizada baseou-se na revisão bibliográfica sobre a temática, na análise do documentário "Positivas" e em algumas narrativas de mulheres soropositivas de Presidente Prudente- SP. Os resultados indicam que o grau de escolarização desempenha um papel importante na vida dessas mulheres, já que quanto maior for o grau de escolarização maior será sua autonomia de exigir do (s) parceiro (os) o uso do preservativo.

Palavras-chave: Feminização do HIV/AIDS; Soropositivas; Sexualidade; Prevenção e Grau de escolaridade.

\section{INTRODUÇÃO}

Não se pode negar que quando se discute sobre a contaminação do human immunodeficiency virus (HIV) entre mulheres, a sexualidade também é discutida, de forma muitas vezes preconceituosa. Por isso, iniciamos este texto mostrando a definição científica sexualidade de acordo com a literatura e ao longo do texto mostraremos como a sexualidade das mulheres é vista pela sociedade desde os séculos anteriores. Para isso serão referenciados neste artigo os seguintes autores: Louro (2004; e 2007), Foucault (1988), Duby (2001), Muribeca (2010), entre outros.

Por milênios, o corpo feminino foi envolto em uma áurea de profundo mistério, o que deu margens a muitos equívocos. Esse corpo anatomicamente considerado imperfeito se prestava a todo tipo de associações com o mal, por parte da religião, e com as enfermidades, por parte da ciência. (MURIBECA, 2010, p.101).

O principal objetivo deste estudo é fornecer reflexões acerca da temática da Feminização do human immunodeficiency virus (HIV) no município de Presidente Prudente, bem como sobre as consequências da ausência do grau de escolaridade como um dos fatores do aumento dos casos de contaminação pelo human immunodeficiency virus (HIV) entre as mulheres soropositivas. 
Por questões que envolvem preceitos religiosos, moralismo e preconceitos discutir sobre sexualidade configuram-se como um tabu que necessita ser rompido, conforme Foucault (1988) a sociedade normatiza a sexualidade, pois pode ser entendida como um dispositivo que "[...] o poder organiza em suas capturas dos corpos, suas materialidades, suas forças, suas energias, suas sensações, seus prazeres"(p. 205). Sendo assim, as diversidades sexuais rompem com os padrões normatizados da sociedade.

Louro (2004) aponta que com o surgimento da Adquired Immunological Deficiency Syndrome (AIDS) em 1980 e a associação da doença com a homossexualidade reforçou ainda mais a homofobia social. A autora destaca que:

O combate à doença também acarreta um deslocamento nos discursos a respeito da sexualidade - agora nos discursos se dirigem menos às identidades e se concentram mais nas práticas sexuais (ao enfatizar, por exemplo, a prática do sexo seguro). (LOURO, 2004, p.35).

Sobre a questão da sexualidade Louro (2007) aponta que:

Muitos consideram que a sexualidade é algo que todos nós, mulheres e homens, possuímos "naturalmente". Aceitando essa ideia, fica sem sentido argumentar a respeito de sua dimensão social e política ou a respeito de seu caráter construído. A sexualidade seria algo "dado" pela natureza, inerente ao ser humano. Tal concepção usualmente se ancora no corpo e na suposição de que todos vivemos nossos corpos, universalmente, da mesma forma. No entanto, podemos entender que a sexualidade envolve rituais, linguagens, fantasias, representações, símbolos, convenções... Processos profundamente culturais e plurais. (LOURO, 2007. p. 11).

Conforme a literatura sexualidade não se refere apenas ao ato sexual propriamente dito é um aspecto importante de nossa personalidade, pois representa o modo de como nos sentimos como homens ou como mulheres, o interesse por sujeitos do gênero oposto ou sujeitos do mesmo gênero, o modo de como agimos, pensamos, falamos ou nos vestimos. Enfim a sexualidade referese à maneira em que vivemos.

Adquired Immunological Deficiency Syndrome $\left(\operatorname{SIDA}^{1}\right)$ é uma doença crônica causada pelo vírus human immunodeficiency virus $\left(\mathrm{HIV}^{2}\right)$ que afeta o sistema imunológico dos seres humanos tornando o sujeito infectado suscetível à contaminação por doenças "oportunistas", como por exemplo, gripes, resfriados, infecções viróticas etc. O Sistema Imunológico exerce um papel muito

\footnotetext{
${ }^{1}$ SIDA (Síndrome da Imunodeficiência Adquirida): No Brasil muitos documentos utilizam essa sigla em uma tentativa de tradutibilidade para a língua portuguesa.

${ }^{2}$ HIV é a abreviação usada para se referir ao vírus causador da AIDS. Disponível em: $\leq$ http://www.suapesquisa.com/aids>Acesso em: 13 de Junho de 2011.
} 
importante em nosso organismo, pois ele é responsável por "proteger" o corpo, dificultando invasões de vírus e bactérias que comprometem a nossa saúde. (BRAMBILLA, 2004).

Quando o sujeito é contaminado pelo vírus da Adquired Immunological Deficiency Syndrome (AIDS) o organismo fica comprometido e não consegue exercer sua função corretamente, pois o human immunodeficiency virus (HIV) enfraquece a defesa do organismo tornando-o apto a se contaminar por qualquer infecção "oportunista" agravando o quadro clínico do sujeito infectado. (BRAMBILLA, 2004). Sabe-se que a Adquired Immunological Deficiency Syndrome (AIDS) é uma doença crônica, entretanto há tratamento, e os medicamentos são disponibilizados pelo SUS ${ }^{3}$. Ser soropositivo não significa estar fadada a morte. Muitos soropositivos que estão em tratamento apresentam uma expectativa de vida muito longa devido aos coquetéis.

Brambilla (2004) lembra que a eficácia do tratamento depende do entusiasmo dos pacientes, a autora afirma que:

Os remédios anti-retrovirais necessitam dos pacientes, toda força de vontade, aceitação e cuidados com a saúde por causa dos efeitos colaterais. É de extrema necessidade que o paciente seja avaliado pelo médico constantemente, para verificar se o coquetel está fazendo efeito ou se há necessidade de ser mudado o esquema dos medicamentos. (BRAMBILLA, 2004, p. 29).

Para ter uma ideia na década de 1980 a doença ficou conhecida como "peste gay", pois os primeiros casos de Adquired Immunological Deficiency Syndrome (AIDS) foram diagnosticados em homossexuais, e para alguns sujeitos a doença soava como uma maldição ou castigo divino, atribuído a um agrupamento de sujeitos cuja orientação sexual não é aceita por boa parte da sociedade. (RUBIO, 1997).

Infelizmente há aqueles que por serem heterossexuais jugam-se imunes ao contágio da doença. Em uma das edições do Big Brother Brasil (BBB) um dos participantes do programa Marcelo Dourado manifestou abertamente que "héteros não pegam essa doença". Esta fala infeliz é uma grande incoerência, e uma manifestação preconceituosa, pois como comprovam os estudos feitos sobre a temática, o HIV/AIDS afeta qualquer camada popular bem como qualquer sujeito sexualmente ativo ou não, pois alguns soropositivos contraem ou contraíram a doença através da transmissão vertical, ou seja, durante o nascimento se a mãe for soropositiva. Portanto deve considerar que os heterossexuais também são suscetíveis ao contágio pela doença. Há ainda aqueles que têm a ousadia de dizer que as doenças e principalmente Adquired Immunological 
Deficiency Syndrome (AIDS) são jogos de marketing criados para vender produtos e medicamentos.

A Adquired Immunological Deficiency Syndrome (AIDS) pode ser transmitida por meio de sangue ou fluidos corporais contaminados e também por meio da inseminação artificial e transplante de órgãos. E no caso de práticas sexuais protagonizados por lésbicas não há risco de contaminação a não ser que ocorra algum tipo de lesão durante a prática e uma das mulheres esteja contaminada pelo o vírus human immunodeficiency virus (HIV), por isso o ideal é que os objetos eróticos sejam individuais. (RUBIO, 1997).

Como se sabe no início da epidemia da Adquired Immunological Deficiency Syndrome (AIDS) houve uma associação equivocada da disseminação da doença com as práticas sexuais protagonizadas por sujeitos do mesmo gênero, porém diversas pesquisas em relação à temática e a evolução da própria epidemia demonstraram que as coisas não funcionavam como queria o preconceito de alguns. (RIOS; ALMEIDA; PARKER, 2007). É importante lembrar que homossexuais, assim como usuários de drogas e profissionais do sexo não são os únicos sujeitos vulneráveis ao human immunodeficiency virus (HIV). Essa afirmação pode ser verificada através da análise do documentário "Positivas" (Modo Operante Produções, 2010) a que aborda de forma direta e clara os principais fatores da Feminização da AIDS no Brasil.

A feminização do HIV se dá por meio de fatores diversos, assim como desigualdade de gênero, desigualdades étnico-raciais; a pobreza; a violência doméstica e sexual; estigma e violação dos direitos humanos. A questão do grau de escolaridade também é um fator que determina o aumento dos casos de AIDS entre as mulheres. O grau de escolaridade é também considerado um dos fatores determinantes para o aumento da feminização do HIV, pois o desconhecimento é um elemento crucial da disseminação do HIV/AIDS. (RIBEIRO; ANDRADE; BRAGA, 2012, sp)

Sobre a questão da vulnerabilidade Sanches (1999) ressalta que:

A percepção de vulnerabilidade pessoal pelas mulheres é importante e necessária, mas não é suficiente para determinar mudanças de comportamento. Diferentes grupos sociais apresentam lógicas e concepções diferenciadas sobre a saúde e doença. O conceito de risco é um dos mais complexos da epidemiologia, com implicações importantes para a educação em saúde. A noção que cada pessoa tem acerca do risco a que está exposta tem, frequentemente, pouco a ver com o risco real. Mesmo aqueles que sabem bastante sobre HIV/AIDS e sobre a importância de adotar medidas de proteção, admitem que nem sempre tomam as devidas precauções. (SANCHES, 1999, p.77). 
Neste sentido é necessário levar em conta que a AIDS não é mais uma doença segmentada que atinge apenas um determinado grupo de risco. Todos os sujeitos que são sexualmente ativos também são vulneráveis e podem contrair a doença, desde que não tomem as medidas preventivas, como, por exemplo, o uso do preservativo em relações sexuais.

\section{METODOLOGIA:}

Para realizar este estudo foi preciso pesquisar em sites de buscas na internet filmes que tratavam sobre a temática da feminização do human immunodeficiency virus (HIV), pois é difícil o acesso a filmes sobre essa temática em vídeo locadoras. A partir das buscas foi possível adquirir o documentário "Positivas" dirigido pela jornalista e cineasta Susanna Lira com o objetivo de mostrar como o muro do preconceito é frágil e desinformado, que cega toda a sociedade, revelando que nem mesmo as mulheres monogâmicas estão protegidas da contaminação do vírus human immunodeficiency virus (HIV.)

Para verificar os dados apresentados no documentário, essa pesquisa lançou mão de aplicar via e-mail, sem identificação social do servidor, um questionário para duas soropositivas de Presidente Prudente. Assim como no documentário, os resultados das narrativas das participantes prudentinas sinalizam que suas vidas pessoais após a contaminação são e continuam normais. $A$ diferença é que elas precisam tomar os medicamentos todos os dias para controlar a manifestação do vírus no organismo.

\section{RESULTADOS}

Dados cedidos pela Central Única de Trabalhadores (CUT) de Presidente Prudente em 2010 demonstram que de 247 soropositivas atendidas na cidade 4 são analfabetas, 88 concluíram o $1^{\circ}$ grau, 93 tem o $1^{\circ}$ grau incompleto, 20 concluíram o $2^{\circ}$ grau, outras 20 tem o $2^{\circ}$ grau incompleto, 17 concluíram o ensino superior e 5 tem o ensino superior incompleto.

Os resultados indicam que o grau de escolarização desempenha um papel importante na vida dessas mulheres, já que quanto maior for o grau de escolarização maior será sua autonomia de exigir do (s) parceiro (os) o uso do preservativo. Quando discutimos sobre o aumento de infecção do human immunodeficiency virus (HIV) entre mulheres em é necessário discutir sobre a questão da vulnerabilidade que é analisada por alguns autores como um problema que atinge principalmente as mulheres empobrecidas e analfabetas, pois o fato de não ter frequentado todo o curso escolar limita sua percepção sobre os riscos que correm de infecção. 


\section{DISCUSSÃO}

Para compreender o aumento da contaminação do HIV/AIDS entre mulheres é necessário levar em conta a maneira de como as mulheres foram educadas em conceber a sexualidade. Em nossa sociedade é nítido perceber que a discussão sobre sexualidade envolve preconceitos, preceitos religiosos e moralismo. Aquelas mulheres que se propõe a discutir sobre sexualidade sem manifestar algum tipo de constrangimento são vistas como vulgares aos olhos das outras que se julgam "puras" e "respeitosas".

No século XII as mulheres eram vistas pela sociedade como seres malignos, pois eram luxuriosas, indóceis e feiticeiras, elas também faziam o uso do adultério em busca de prazer. Para a sociedade em geral elas deveriam ser "dominadas" pelos seus maridos como se fossem propriedades deles, elas deveriam ser submissas aos "seus senhores", isto é, as mulheres deveriam ser bons exemplos para as demais. Os homens deveriam dar proteção para as mulheres em troca elas tinham que satisfazer todos os caprichos de seus maridos (DUBY, 2001).

Historicamente as mulheres foram educadas para serem submissas aos maridos, acatando e respeitando suas decisões sem ter direito de manifestarem suas opiniões e desejos que sempre foram reprimidos. Até os dias atuais as mulheres carregam essas consequências e em relação à Feminização do human immunodeficiency virus (HIV) isso pode ser claramente notado, pois infelizmente as relações desiguais de gênero influenciam de maneira direta ou indiretamente a contaminação do vírus entre elas. Isso é um tabu que necessita ser interrompido e que diz respeito à dificuldade que as mulheres têm em exigir dos parceiros o uso do preservativo. É necessário que as mulheres percebam que o uso do preservativo é fundamental mesmo em relações monogâmicas.

Muitos acreditam que a confiança pode "imunizar" contra a infecção pelo HIV. O relacionamento conjugal é construído sobre a forte segurança do confiar e acreditar no outro. E isto é criado através de determinadas estratégias como, por exemplo, no relacionamento conjugal a confiança está pautada sobre o controle que um parceiro tem sobre as rotinas e horários do outro (a). O sujeito passa a conhecer os horários, sabe onde ele está e o que faz durante todo o dia. Esta administração também pode ser vista como confiar no parceiro e ter conhecimento de todos os seus passos. (OLTOMARI; OTTO, 2006, p.60).

O Ministério da Saúde (BRASIL, 2004) aponta que no Brasil a iniciação sexual feminina ocorre precocemente ocasionada por motivos diversos dentre eles estão à pressão social, a manifestação espontânea e até mesmo a violência sexual. 
Socialmente a representação das mulheres é construída pela ideia da família nuclear burguesa em que elas são submissas ao marido, cuida da casa e dos filhos e são monogâmicas. $E$ aquelas que não se enquadram nesse perfil são julgadas como mulheres de má índole, e má influencia para as mulheres "castas".

\section{CONCLUSÃO}

As mulheres sempre lutaram pelos seus direitos e tiveram algumas conquistas como, por exemplo, o direito ao voto, o direito a instrução escolar e a inserção no mercado de trabalho, porém mesmo tendo esses direitos garantidos elas ainda sofrem preconceitos. A mulher é vista como responsável pelo lar é dever dela zelar pelo bem estar da família. Muitas mulheres trabalham para ajudar o marido no sustento da família, e como não tem condições financeiras de contratar uma empregada doméstica elas mesmas cansadas da rotina desgastante de trabalho, são responsáveis pela realização de tarefas domésticas.

Entretanto é um grande equívoco da sociedade que tem um poder aquisitivo melhor pensar que estão livres do vírus human immunodeficiency virus HIV, pois a Adquired Immunological Deficiency Syndrome (AIDS) é uma doença que atinge todas as camadas sociais. Não há um determinado grupo de risco para a disseminação da doença.

A Adquired Immunological Deficiency Syndrome (AIDS) é uma doença que não tem cura, entretanto alguns estudos estão sendo feitos para que isso ocorra, porém infelizmente ainda não é possível prever esse fato.

Como diversos trabalhos acadêmicos realizados sobre o human immunodeficiency virus (HIV) e inclusive este ressalta que a única forma de evitar a contaminação continua sendo a prevenção para aqueles que são soro discordantes e para aqueles que são soropositivos o tratamento correto pode minimizar os sofrimentos causado pela doença.

\section{REFERÊNCIAS}

AIDS/HIV. Disponível em: <http://www.suapesquisa.com/aids>Acesso em: 13 de Junho de 2011.

BRAMBILLA, A. Diagnóstico econômico do tratamento dos portadores de HIV/AIDS no município de Presidente Prudente/SP. 2004.75f. Trabalho de conclusão de curso (Graduação em Ciências Contábeis)- Faculdades Integradas "Antônio Eufrásio de Toledo", Faculdade de Ciências Econômicas e Administrativas de Presidente Prudente, Presidente Prudente, 2004. 
BRASIL. Ministério da Saúde. Secretaria de Atenção à Saúde. Departamento de Ações Programáticas Estratégicas. Política nacional de atenção integral à saúde da mulher: princípios e diretrizes - Brasília: Ministério da Saúde, p. 01-82, 2004.

DUBY, G. Os pecados das mulheres. In: DUBY, G. Damas do século XII. São Paulo. Companhia das letras; 2001, p.11-68.

FOUCAULT, M. História da sexualidade: a vontade de saber. Rio de Janeiro: Graal, 1988. V.1.

LOURO, G.L. Uma política pós-identitária para a educação. In: LOURO, G. L. (Org.). Um corpo estranho: ensaios sobre sexualidade e teoria queer. Belo Horizonte: Autêntica, 2004.

LOURO, G.L. Pedagogias da sexualidade. In: LOURO, G. L. (Org.). O corpo educado: pedagogias da sexualidade. 2a ed.3aㅡ reimpressão_Belo Horizonte: Autêntica, 2007; p. 09 -52.

MURIBECA. Maria das Mercês Maia. Das origens da sexualidade feminina ao feminino nas origens da psicossexualidade humana. Estudos de Psicanálise - Aracaju- n. 33 - p.101-108 - Julho. 2010. Disponível em: <http://www.cbp.org.br/origenssexualidadefeminina.pdf> Acesso em: abril de 2013.

OLTRAMARI, Leandro Castro; OTTO, Liliane Schuch. Conjugalidade e AIDS: um estudo sobre infecção entre casais. Psicol. Soc., Porto Alegre, v. 18, n. 3, Dec. 2006. Disponível em: $<$ http://www.scielo.br/scielo.php?script=sci arttext\&pid=S010271822006000300008\&lng=en\&nr $\underline{\mathrm{m}=\mathrm{iso}}>$. Acesso em 02 de abril de 2013.

POSITIVAS. Filme. Direção e Roteiro de Susanna Lira. Produção executiva de Luciana Freiras. Rio de Janeiro, Modo Operante Produções, 2010. DVD (78 min) Cor.

RIBEIRO, A. I. M.; ANDRADE, J. ; BRAGA, K. D. S. As consequências da ausência do Grau de Escolarização nas Soropositivas no município de Presidente Prudente- SP. In: Congresso Internacional de Educação Pesquisa e Gestão, 4., 2012, Ponta Grossa_ PR. Anais ... Ponta Grossa_ PR. 2012.

RIOS, F. L.; ALMEIDA, V. de; PARKER, R. (organizadores). Juventude e Homossexualidade: o que os pais precisam saber. 2007. <http://www.vagnerdealmeida.com/Publications/FamiliaHSHLivreto.pdf $>$ Acesso em: 2 de abril de 2013.

RUBIO, A.D. 96 respostas sobre AIDS. São Paulo. Scipione, 1997.

SANCHES, B. R. K. A AIDS e as mulheres jovens: uma questão de vulnerabilidade. [Doutorado] Fundação Oswaldo Cruz, Escola Nacional de Saúde Pública; 1999. Disponível em: $<$ http://portalteses.icict.fiocruz.br/transf.phpscript=thes cover\&id=000003\&lng=pt\&s> Acesso em: Maio de 2012. 